\title{
MEASURING DIETARY EXPOSURE IN NUTRITIONAL EPIDEMIOLOGICAL STUDIES
}

\author{
BARRIE M. MARGETTS ${ }^{1}$ AND MICHAEL NELSON ${ }^{2}$ \\ ${ }^{1}$ Wessex Institute of Public Health Medicine, University of Southampton, UK \\ ${ }^{2}$ Department of Nutrition and Dietetics, Kings College, University of London
}

\section{CONTENTS}

INTRODUCTION

EPIDEMIOLOGICAL PRINCIPLES RELEVANT TO DIETARY STUDIES. 166

DEFINING EXPOSURE AND OUTCOME .

GENERAL ISSUES TO BE CONSIDERED WHEN ASSESSING DIETARY

EXPOSURES.

166

COMPLEXITY OF DIETARY EXPOSURE . . . . . . . . . . . . 167

DOSE-RESPONSE RELATIONSHIP . . . . . . . . . . . . . . 167

PHYSIOLOGICAL/METABOLIC REQUIREMENTS . . . . . . . . . 167

MULTIPLE FUNCTIONS . . . . . . . . . . . . . . . . . . 168

INTERACTION . . . . . . . . . . . . . . . . . . 168

BIOA VAILABILITY . $\quad . \quad$. . . . . . . . . . . . . . . . . 168

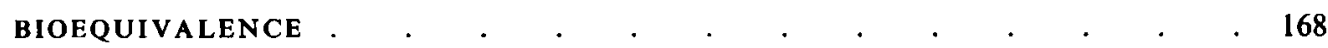

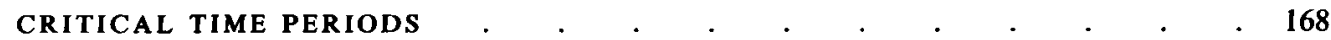

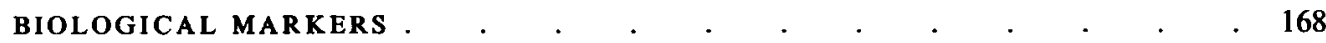

THE RELEVANT EXPOSURE . . . . . . . . . . . . . . 169

EPIDEMIOLOGICAL APPROACHES TO MEASURING

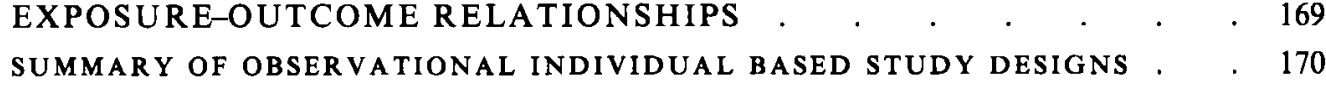

Cohort studies .

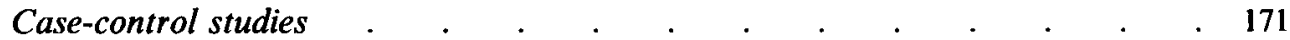

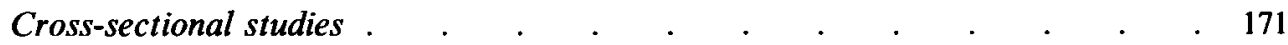

DIETARY MEASURES IN EPIDEMIOLOGICAL STUDIES . . . . . 171

EXPERIMENTAL STUDIES . . . . . . . . . . . . . . . 172

COHORT STUDIES . . . . . . . . . . . . . . 172

CASE-CONTROL STUDIES $. \quad . \quad . \quad . \quad . \quad . \quad . \quad . \quad . \quad$. . . . 173

CROSS-SECTIONAL STUDIES . . . . . . . . . . . . . . . . 174

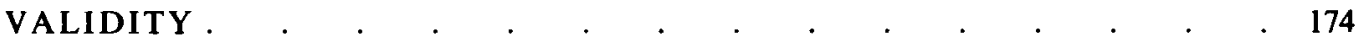

CALIBRATION OF MEASURES. . . . . . . . . . . . . . . 175

REPEATABILITY •. . . . . . . . . . . . . . 175

EXAMPLES OF QUESTIONS AND APPROACHES WHICH MAY BE
USED

SUMMARY. . . . . . . . . . . . . . . . 177

REFERENCES . . . . . . . . . . . . . . . . . . . . 177 


\section{INTRODUCTION}

There is little debate, in general terms, that diet is an important risk factor for most chronic disease. There have been numerous predictions based on best guess estimates about how much disease might be prevented by changes in diet, and no doubt these predictions could be refined by more sophisticated modelling. Recent discussion focuses increasingly around the more precise effects of specific foods and nutrients. There is growing recognition that an understanding about the consumption patterns of foods as well as the nutrients derived from these foods is important in understanding the aetiology of health outcomes. More current data are available for nutrients than for foods.

We believe that an important part of the confusion related to the role of diet in chronic disease aetiology stems from the poor or inappropriate dietary methods used in many studies assessing diet-disease relationships. There are a number of commonly held misconceptions about the requirements for measuring diet in different types of epidemiological studies. This review seeks to summarize what we believe to be the consensus on best practice at the present time.

\section{EPIDEMIOLOGICAL PRINCIPLES RELEVANT TO DIETARY STUDIES}

Epidemiology is classically defined as the study of the distribution and determinants of disease frequency in populations (MacMahon \& Pugh, 1970). Focusing on the determinants of disease, the objective is to assess how exposures are related to outcomes. The capacity to draw causal inferences (establish the determinants) depends on the study design, and a consideration of the effects of chance, bias and confounding on the relationships reported. There is a large literature reviewing the debate around determining causality (Rothman, 1986; Renton, 1994). There is general agreement about the broad principles of good study design, and the strengths and weaknesses of different types of epidemiological study (Beaglehole et al. 1993).

Research should follow a written protocol (which includes a theoretical as well as a practical consideration as to how to conduct the study in the best possible way) which takes into account the effects of chance, bias, and confounding. The number of subjects required should be carefully worked out beforehand.

The way a study is to be analysed and presented for publication needs to be considered at the study design stage as this will influence what data to collect and how they need to be collected. Most epidemiological studies assess the difference or change in risk of disease against differences or changes in dietary exposure: do people who have higher or lower exposure have more or less risk of disease? The difference in risk is often expressed in terms of some arbitrary categorization of the distribution of diet within the study population, comparing subjects in different thirds, fourths or fifths of the distribution. The ranking of subjects is thus the key measurement rather than a measure of absolute consumption. Ideally the assessment of risk would include an exact estimate of, for example, how much fruit was eaten and of what type, but this is rarely available (or practical to collect) in most studies (Block et al. 1992). To get to this level of detail may require a more innovative collaboration between field work and laboratory based studies (Margetts, 1994).

\section{DEFINING EXPOSURE AND OUTCOME}

Exposures in nutritional epidemiological studies may be what people eat, the nutrients or non-nutrients contained in those foods, anthropometric measures, biochemical measures of 
nutritional status or clinical assessment. In the context of this discussion we will focus on food and nutrient intake as the exposures of interest. Outcomes may be a disease state; anthropometric measures; physiological measures such as, for example, blood pressure or serum cholesterol; biological markers; or they may be expressed relative to some standard such as, for example, a dietary reference value. Often the term diet-disease relationship is used to describe exposure-outcome relationship, even when disease is not the outcome of interest.

The development of a specific and clearly defined research question leads to a clear understanding of exactly which exposures and outcomes are of interest. It also leads to a clarification of the other factors which need to be measured and taken into account in the interpretation of the study.

\section{GENERAL ISSUES TO BE CONSIDERED WHEN ASSESSING DIETARY EXPOSURES}

When deciding how to measure dietary exposure the following may need to be considered.

\section{COMPLEXITY OF DIETARY EXPOSURE}

Food consists of many substances, not just nutrients. These other substances, such as additives, contaminants, chemicals formed in the preparation of foods, natural toxins, other naturally occurring compounds and other as yet unknown compounds may all affect disease, and may all therefore be important. It is not adequate to equate nutrient intake with food intake. It is therefore essential to frame the objective of the assessment of dietary exposure as specifically as possible. For example, there has been growing interest recently in the protective effects of fruits and vegetables on risk of cancer, where the effect may be related to previously unmeasured constituents in the fruits and vegetables (Block $e t$ al. 1992). Attributing the protective effect to vitamin $C$ and $\beta$-carotene alone may be misleading (Block, 1992).

\section{DOSE-RESPONSE RELATIONSHIP}

A food and its components (nutrients and other substances) are complex and may have different functions and physiological effects at different levels. There is a level at which optimal function exists and which may be affected by the availability of adequate levels of other nutrients. For example, vitamin A at one extreme of intake may result in a deficiency state and at the other extreme may result in toxicity (Willett, 1990). Somewhere in between is the amount at which optimal function occurs. Studying vitamin A intake at different points in this spectrum may give apparently different results. It may be important therefore to know prior to the study where in this spectrum the participants are likely to be and to consider whether this may be likely to affect the exposure-outcome relationship.

\section{PHYSIOLOGICAL/METABOLIC REQUIREMENTS}

The requirements for nutrients may be quite different in growth, ageing, pregnancy or in states of infection, for example. It is therefore essential to have a clear understanding of the physiological state of the population group of interest as the need for and use of nutrients may be quite different in these different groups. 


\section{MULTIPLE FUNCTIONS}

A nutrient may have more than one function and these functions may have different effects on the outcome of interest.

\section{INTERACTION}

The effect of one nutrient may differ according to the level of another nutrient. Protein intake may affect a disease process differently when total energy intake or levels of other essential nutrients are inadequate. The need for, and the use of, nutrients may be quite different at different levels of total energy intake, and under different physiological states or under different physical stresses. Recent studies suggest a complex interaction between vitamin $A$ intake and iron, so that giving vitamin $A$ alone and without consideration of the iron status may have a different effect on the outcome of interest (Ahmed et al. 1993).

\section{BIOAVAILABILITY}

Nutrient intake is not equivalent to biological availability. There are a complex series of steps through which a substance must pass before it becomes available at the site of action. There may be interactions which either enhance or impede at each stage of the process. Circulating levels of some nutrients are controlled at the level of absorption, whereas others are controlled at the level of excretion. It may therefore be very misleading to assume that the level of a nutrient reported in Tables of Food Composition represents the functionally available level. The relationship between the measured exposure (and outcome) and the relevant exposure (and outcome) needs to be carefully established if any understanding is to be gained about the cause-effect relationship between the measured exposure and its effect on the measured outcome.

\section{BIOEQUIVALENCE}

Some nutrients have bioequivalence. For example, niacin can be synthesized from tryptophan. An experimental study undertaken to investigate the effect of depletion/ repletion on niacin status will need to take account of the potential effect that levels of tryptophan may have on niacin status.

\section{CRITICAL TIME PERIODS}

There may be critical time periods in the development of an outcome where the level of intake of a nutrient may play a vital role. At other times the same level of nutrient may have no effect on outcome. This may be the situation, for example, with folate and neural tube defects (Medical Research Council Vitamin Research Group 1991).

\section{BIOLOGICAL MARKERS}

Biological markers of dietary intake may relate to short, medium or long term intake, and their role as indicators of exposure-outcome relationships may have a different value for 
each exposure of interest. For a more complete discussion see Bates et al. (1991) and van't Veer (1994); the same issues regarding measurement error apply as much to biological measures as to any other.

\section{THE RELEVANT EXPOSURE}

A specific level of a nutrient measured as a concentration in blood or serum may not reflect the balance or status of that nutrient in an individual, and may therefore be an inappropriate measure of the relevant exposure.

It should be clear from the above that diet is a complex exposure to measure. It is desirable that before commencing a study the possible effects of the above factors be considered, to ensure that the most appropriate aspects of exposure are measured. Having an idea about the underlying mechanisms believed to be involved will help clarify some of these issues. Inter alia, it is essential to consider the nutritional status of subjects included in a study as well as the effects which factors such as age, gender and other aspects of health (for example, concomitant disease) may have on their exposure.

\section{EPIDEMIOLOGICAL APPROACHES TO MEASURING EXPOSURE-OUTCOME RELATIONSHIPS}

Broadly, epidemiological studies may be divided into experimental and observational investigations (Table 1). The primary distinction between these types of study is that in experimental investigations exposures are assigned to subjects (randomly and under carefully controlled conditions) by the investigator, whereas in observational studies the investigator has no control over the way in which subjects are exposed.

Practical and ethical issues may be important in determining which approach is used to address a particular question. In general, experimental studies provide the strongest evidence for the effect of an exposure on an outcome. However, it is not ethical (or permissible) to do experimental studies where the exposure is known to be harmful. Under these circumstances non-experimental study designs must be used.

In observational studies the investigator may be able to exploit 'natural experiments' where exposure is restricted in some groups in the community compared with other groups - for example, groups of vegetarians who avoid meat and who have other dietary differences compared with omnivores. Under some circumstances, by careful selection of a comparison group, it may also be possible to match on potentially confounding factors in observational studies, such as, for example, comparing Seventh-Day Adventist vegetarians with Mormon omnivores where consumption of alcohol, use of tobacco and other lifestyle factors may be similar (Rouse et al. 1981).

Another way of classifying investigations is according to whether measurements of exposure and outcome are made on populations or individuals. It is possible to have population based experimental studies, such as community trials, and population based observational investigations, such as ecological studies. Similarly, both experimental and observational investigations can be conducted among individuals. Although population based studies consist of data collected from individuals (e.g. death certificate diagnosis or food consumption data), exposure measures are only related to outcome measures at the group or aggregate level.

In an individual based study it is possible to relate exposure and outcome measures more directly. An advantage therefore of individual based studies over population based studies 
Table 1. Distinction between types of epidemiological studies

\begin{tabular}{lll}
\hline & & \multicolumn{1}{c}{ Study group } \\
\cline { 3 - 4 } & Populations & Individuals \\
\hline $\begin{array}{l}\text { Observational } \\
\text { (descriptive or analytical) }\end{array}$ & Ecological & $\begin{array}{l}\text { Cross-sectional } \\
\text { Case-control } \\
\text { Cohort } \\
\text { Clinical or field } \\
\text { (trial or intervention) }\end{array}$ \\
\hline
\end{tabular}

is that they allow the direct estimation of the risk of disease in relation to exposure. It is possible to assess, for example, whether individuals who eat more fat have higher rates of heart disease. With population based methods it might be shown that populations having higher fat intakes also have higher rates of heart disease, but it would not necessarily follow, nor can it be asserted, that the excess of heart disease occurred in those individuals who consumed more fat.

It is also possible in individual based studies to measure, and take into account in the analysis, the effects which other factors may have on the relationship under investigation. In population based studies it is usually only possible to consider the effects of a limited number of other factors, and it is therefore more likely that an association which is found could be due to the effects of other unmeasured factors. For more details on epidemiological methods other texts are recommended (Schlesselman, 1982; Kelsey et al. 1986; Meinert, 1986; Rothman, 1986; Breslow \& Day, 1987; Hennekens \& Buring, 1987).

\section{SUMMARY OF OBSERVATIONAL INDIVIDUAL BASED STUDY DESIGNS}

\section{Cohort studies}

Cohort studies can be conducted either prospectively (concurrently) or retrospectively (non-currently). A prospective cohort study defines a population in the present, measures relevant exposures, and follows the subjects into the future to ascertain the development of disease. The disease status is then determined in different categories of the baseline and subsequent exposure. A retrospective cohort study uses measures of exposure from the past. The measures of exposure may have been collected prospectively in the past, or markers of past exposure (if available) may be collected in the present. Many examples may be found of prospective cohort studies where diet has been measured at baseline (Stemmermann et al. 1984; Bostick et al. 1993; Giovannucci et al. 1994). A large multicentre prospective cohort study is under way in Europe with baseline assessment of dietary intake and blood collection which will be stored for subsequent biological measures (Riboli, 1992). There are fewer retrospective cohort studies and these tend to have fewer dietary data available. An example of a retrospective cohort study is that of men born in Hertfordshire between 1911 and 1921, defined from health visitor records collected prospectively over those years. These men were subsequently followed up through the National Health Service central register to determine vital status. The mortality experience of these men was then related to birth weight and change in weight over the first year of life to determine if there was any association with rates of ischaemic heart disease (Barker $e t$ al. 1989). 


\section{Case-control studies}

Persons with an outcome or disease (referred to as cases) are compared with persons who do not have the disease (referent group or controls). The prevalence of past exposure to known or suspected risk factors is measured in each group and from this the risk ratio for the effect of each measured exposure can be estimated. In principle a case-control study reconstructs by sampling and with very much less effort the outcome of the cohort study (Coggon; 1991).

The primary concern, with respect to the validity of such studies, is whether there is differential misclassification between cases and controls. This may often occur, for example, where a case may reflect on past diet differently from a control who may have had no reason to look back over what they used to eat in the past. By careful study design and sample selection it may be possible to avoid differential misclassification. For example, in a study of neural tube defects the selection of both a community and hospital based control with another malformation unrelated to neural tube defects, but which may evoke a similar intensive recall of past diet, may provide a suitable basis on which to compare differences in diet between these groups. What then remains is non-differential misclassification which arises because of random factors connected with subjects and errors in the way, for example, diet has been measured. In terms of estimating the effect of exposure on outcome, nondifferential misclassification will tend to attenuate (weaken) the measured effect. Differential misclassification, on the other hand, can work in either direction.

\section{Cross-sectional studies}

Cross-sectional studies measure exposure and outcome at the same point in time. That is, current, not past exposure (as in a case-control study) to the cause is documented in the population sample. Some writers may describe these as prevalence surveys.

It is difficult in cross-sectional studies to determine the nature of the relationship between the measured exposure and outcome. It is not possible to say whether the exposure caused the outcome or vice versa. If the exposure measure is elevated, it is not possible to say whether the elevation was a result of the outcome or was in the causal pathway.

\section{DIETARY MEASURES IN EPIDEMIOLOGICAL STUDIES}

Table 2 summarizes the dietary methods which may be appropriate for use in different types of epidemiological studies. There is no one measure of diet which is appropriate for all sorts of study designs, and the art of doing good research is to select the measure of exposure which is optimal for the study question under consideration.

In broad terms dietary assessment measures can be considered at population, household or individual level. For each a variety of methods is available (Bingham \& Nelson, 1991). A resource manual for such methods has recently been published (Kohlmeier, 1994). There have been many reviews of the strengths and weaknesses of the different dietary survey methods (Block, 1982; Bingham, 1987; Cameron \& Van Staveren, 1988). Individual based measures may be broadly defined as either measuring usual intake (food frequency, dietary history) or current (dietary record or recall) intake. Usual intake refers to measures which are designed to reflect longer term (past) intake and do not record what an individual ate on any particular day. Current intake refers to a measure of food actually eaten in the present or near past. The objective in this review is to place the use of these methods into an epidemiological context.

For the individual based observational studies (cohort studies, case-control studies and cross-sectional studies) it may not always be necessary to characterize an individual's diet 
Table 2. Summary of dietary methods commonly used in different epidemiological studies

\begin{tabular}{|c|c|c|c|c|}
\hline & \multicolumn{4}{|c|}{ Study group } \\
\hline & \multicolumn{2}{|c|}{ Populations or households } & \multicolumn{2}{|r|}{ Individual } \\
\hline & Study design & Dietary assessment & Study design & Dietary assessment \\
\hline \multirow[t]{3}{*}{$\begin{array}{l}\text { Observational } \\
\text { (descriptive or } \\
\text { analytical) }\end{array}$} & Ecological & $\begin{array}{l}\text { Food balance sheets; } \\
\text { household inventory }\end{array}$ & Cross-sectional & $\begin{array}{l}\text { Current ( } 24 \text { h record or recall) } \\
\text { or usual (dietary history or } \\
\text { FFQ) consumption; biological } \\
\text { assays }\end{array}$ \\
\hline & & & Case-control & $\begin{array}{l}\text { Usual consumption in the past: } \\
\text { FFQ or, if diet constant, } 24 \mathrm{~h} \\
\text { recall; biological assays limited }\end{array}$ \\
\hline & & & Cohort & $\begin{array}{l}\text { Usual consumption in the } \\
\text { present, FFQ; questions on } \\
\text { preparation of foods, } \\
\text { supplement use; biological } \\
\text { assays, nested analyses of } \\
\text { assays }\end{array}$ \\
\hline $\begin{array}{l}\text { Experimental } \\
\text { (trial or inter- } \\
\text { vention) }\end{array}$ & Community & $\begin{array}{l}\text { As above, or individual } \\
\text { assessment in subsets } \\
\text { (usual or current } \\
\text { consumption) }\end{array}$ & Clinical or field & $\begin{array}{l}\text { Detailed dietary record (no. of } \\
\text { days depends on nutrient of } \\
\text { interest); biological assays }\end{array}$ \\
\hline
\end{tabular}

FFQ, food frequency questionnaire.

as is the case in experimental studies in individuals. A group mean estimate of exposure may be adequate. In observational studies the objective is to compare exposure levels between groups who have different outcomes. The primary concern, with respect to the validity of such studies, is whether there is any differential misclassification between different outcome groups.

\section{EXPERIMENTAL STUDIES}

There is a variety of approaches which can be used in individual based experimental studies where the effect of dietary change on some outcome measure is being studied. In very carefully controlled studies where subjects are given amounts of foods, and any waste is measured, aliquots or duplicate meals are taken and the nutrient of interest is measured directly in food; no dietary data are recorded from the subjects themselves. In less tightly controlled studies, where subjects are given dietary guidelines to follow but are allowed to select their own food, an accurate assessment of the individual's diet is required. Diet is measured by a weighed record, with the required number of days of recording (to take account of within-person variability) calculated beforehand.

\section{COHORT STUDIES}

In cohort studies the exposure is measured in the present (or at a point in time before the outcome is known in retrospective cohort studies) and subjects are followed forward in time to ascertain outcome. If the objective is to characterize group mean exposures and relate them to group outcome, a measure of usual consumption is adequate. Willett (1990) and 
Nelson (1991) have reviewed the literature on the use of food frequency amount questionnaires and have shown that they can provide reliable information about intake. For example, Willett and colleagues compared a 61 item food frequency amount questionnaire with a $28 \mathrm{~d}$ dietary record collected over one year and showed good agreement between the estimates derived from the two methods (Willett et al. 1987). However, if the objective is to relate data at the level of the individual, more detailed characterization of the individual's diet may be required, in a similar way to individual based experimental studies.

The choice of method to measure exposure will often depend on practical considerations related more to the sample size required to obtain sufficient end points or outcomes (for example, death from a specific disease, a morbid state such as a hip fracture, or a physiological measure such as a change in blood pressure). Cohort studies often contain many thousands of subjects, which limits the method of measuring exposure to one which can be completed by the subject themselves and returned by post. There is a move toward using a nested case-control design within a cohort study to reduce the cost of biochemical assays and other analyses. Data are collected from all subjects in the cohort under study, but the analysis of samples is done on selected subjects only, the case (or person with the outcome of interest) and a group of randomly selected controls (subjects without the outcome of interest) from within the cohort.

\section{CASE-CONTROL STUDIES}

In a case-control study, information can be obtained on many exposure variables, although the validity of this information may be limited by the fact that the data were collected retrospectively. This is particularly a problem in dietary studies where food intake may have changed as a result of the disease process. Ideally the measure of exposure should cover the period in time when the exposure is believed to cause the disease to develop (if that is the hypothesis being tested). Past diet, not the present diet, may therefore be the exposure of interest. If current diet is measured as a proxy for past diet it must be assumed that diet has remained stable over time. If subjects are asked to recall their past diet, there is good evidence to suggest that their current diet influences their recollection of what they thought they ate in the past. There have been a number of studies, reviewed recently (Nelson 1991), that indicate that people often exhibit a 'recency' effect, and recall past intake to be more like present intake than that which was actually consumed. It has recently been shown that when risk of cancer was assessed in the Nurses Health Study using either a prospective or retrospective estimate of diet in the same individuals, the retrospective estimate tended to overestimate the risk compared with that using the prospective estimate (Giovannucci et al. 1993). It is possible, however, that past intake can be estimated and that it represents a better approximation of what was consumed in the past than a measure of current diet, especially when the disease process itself may have a marked influence on current diet (Nelson, 1991). However, provided that recall bias of past intake is similar in cases and controls, it may be possible to derive the correct estimate of effect of the exposure on outcome (Lindsted \& Kuzma, 1989). This would not be true if the recency effect were different for cases and controls.

Usually in case-control studies the aim is to measure risk across strata of exposure levels; for example, to determine whether risk of breast cancer increases across categories of fat or energy intake (often divided into thirds or fifths). As long as subjects are correctly classified into the appropriate category, the absolute level of intake does not affect the estimate of risk. It may therefore be possible to use a simpler method (such as a food 
frequency questionnaire or $24 \mathrm{~h}$ recall) of measuring exposure than when an absolute measure of exposure is required, as may be the situation in some cohort or experimental studies.

\section{CROSS-SECTIONAL STUDIES}

Dietary exposure in cross-sectional studies has been measured in a variety of ways depending on the precision of the estimate required. For example, in the recent survey of adults in the UK, Gregory et al. (1990) used a $7 \mathrm{~d}$ weighed record, whereas Cade et al. (1988) used a $1 \mathrm{~d}$ record to estimate group mean intakes in three towns in the UK, and other workers have used food frequency questionnaires to measure group mean intakes. The choice of method can be balanced between the number of subjects and the number of days of dietary data required, depending on which is likely to be more difficult to obtain (Cole, 1991).

\section{VALIDITY}

Validity can be defined as internal and external, the latter sometimes being referred to as generalizability. Internal validity refers to the way the study is conducted. A part of internal validity relates to the validity of the measures used in the study to assess exposure and outcome. For a measure to be valid it must measure what it purports to measure. Without being internally valid a study can never be externally valid. Assessing the external validity of a study requires the exercise of judgement as to which criteria are important in influencing whether the findings of one study in one population sample will apply to another population.

The terms bias, error and misclassification also need to be defined. Bias is a general term which applies to any systematic error in the way a study is conducted, analysed and reported. A study which is not internally valid will give biased information. Error may be defined as either random or systematic, and may occur within or between subjects. Systematic error leads to bias and must be avoided where possible; random error will always occur and should be minimized but may not lead to bias. In reality it is often difficult to separate the effects of different types of error.

Within-subject day-to-day variance is often taken to be random error, such that the mean of the error for each subject equals zero. This assumption underlies the models used to calculate the number of days required to rank subjects with a desired precision (Nelson $e t$ al. 1989). An important source of variation may come from weekly or longer term patterns of intake (Basiotis et al. 1989), or from the influence of menstruation (Gong et al. 1989), such that the within-subject variance calculated over relatively few days' record does not in fact reflect the true extent of variation of 'usual' intake. In consequence, the observed error will not have a mean zero, and the calculated pooled within-subject variance is likely to underestimate the true variance. The estimate of disease risk in relation to diet will thus still be attenuated even when corrections for within-subject variance have been made (Freudenheim \& Marshall, 1988; Borrelli, 1990; Nelson, 1991). While the error is strictly speaking random within-subject error, it straddles the boundary of non-systematic bias in that it varies between subjects and will lead to differential misclassification depending on the differences in patterns between subjects at the time the measurements are taken.

Additional influences on within-subject variance, such as day of the week, month or season, and menstruation, should be noted at the time of recording so that they can be taken into account during analysis. Functions which describe systematic error and nonsystematic bias have been set out by Borrelli (1990). In the presence of random error with 
constant variance, a proportionate systematic error may affect the strength of the diet-disease relationship in either direction, whereas a constant systematic bias has no effect on the risk estimate. However, a proportionate bias may be harmless if the random error is absent or (as is more likely) has a proportionate variance as well. Sources of systematic error and non-systematic bias are equally difficult to assess, whether using prospective or retrospective methods for recording diet. While retrospective methods have more potential sources of bias than prospective methods and may therefore tend to be avoided, there are many epidemiological studies, especially case-control studies, which demand retrospective assessment. Indeed, for some items of consumption such as alcohol and sweets, and for those nutrients such as retinol for which a very large number of days is needed to assess ' usual' intake, retrospective methods to assess recent diet may be preferred. Whatever the aim, identification of the sources of bias is an essential part of nutritional epidemiological research.

Because of the errors which occur in measuring a subject's exposure, that person may be incorrectly placed (compared with the subject's true position) in the distribution of the population exposure. This may be referred to as misclassification. It is essential to have a measure of the likely misclassification which results from using the method selected.

\section{CALIBRATION OF MEASURES}

Before a study begins it is essential to know whether the measuring instrument or method of assessing exposure measures that exposure with the required degree of accuracy. If a previously calibrated measure, which has been used in the same population, is not available then a calibration study is required to determine the relative validity of the measure proposed. Consideration needs to be given as to the best measure of the exposure of interest to act as a 'better' measure of the 'truth', against which to compare the proposed measure. Clearly absolute 'truth' cannot be measured, and hence the use of the term relative validity and calibration study, because realistically all that is possible is a calibration of one measure with another.

\section{REPEATABILITY}

A reliable measure is not necessarily a valid measure, but for a measure to be valid it must be reliable. The reliability or repeatability of the measure, once it has been calibrated, can be assessed during the study by including a repeat measure, even if it is only in a statistically viable subsample. This allows the measure of exposure to be corrected, as suggested by Liu et al. (1978), Freudenheim \& Marshall (1988) and Borrelli (1990). Clayton \& Gill (1991) and Clayton (1994) have recently discussed ways of estimating and remedying measurement error problems. Some caution may be required in correcting poor estimates where a biased exposure has been measured because it may incorrectly inflate the estimate of effect.

\section{EXAMPLES OF QUESTIONS AND APPROACHES WHICH MAY BE USED}

Table 3 seeks to provide some practical examples of the sorts of research questions which are explored in epidemiological studies, study design options which may be used in those studies, together with what measures to use and a consideration of the effects of bias on the study results. 


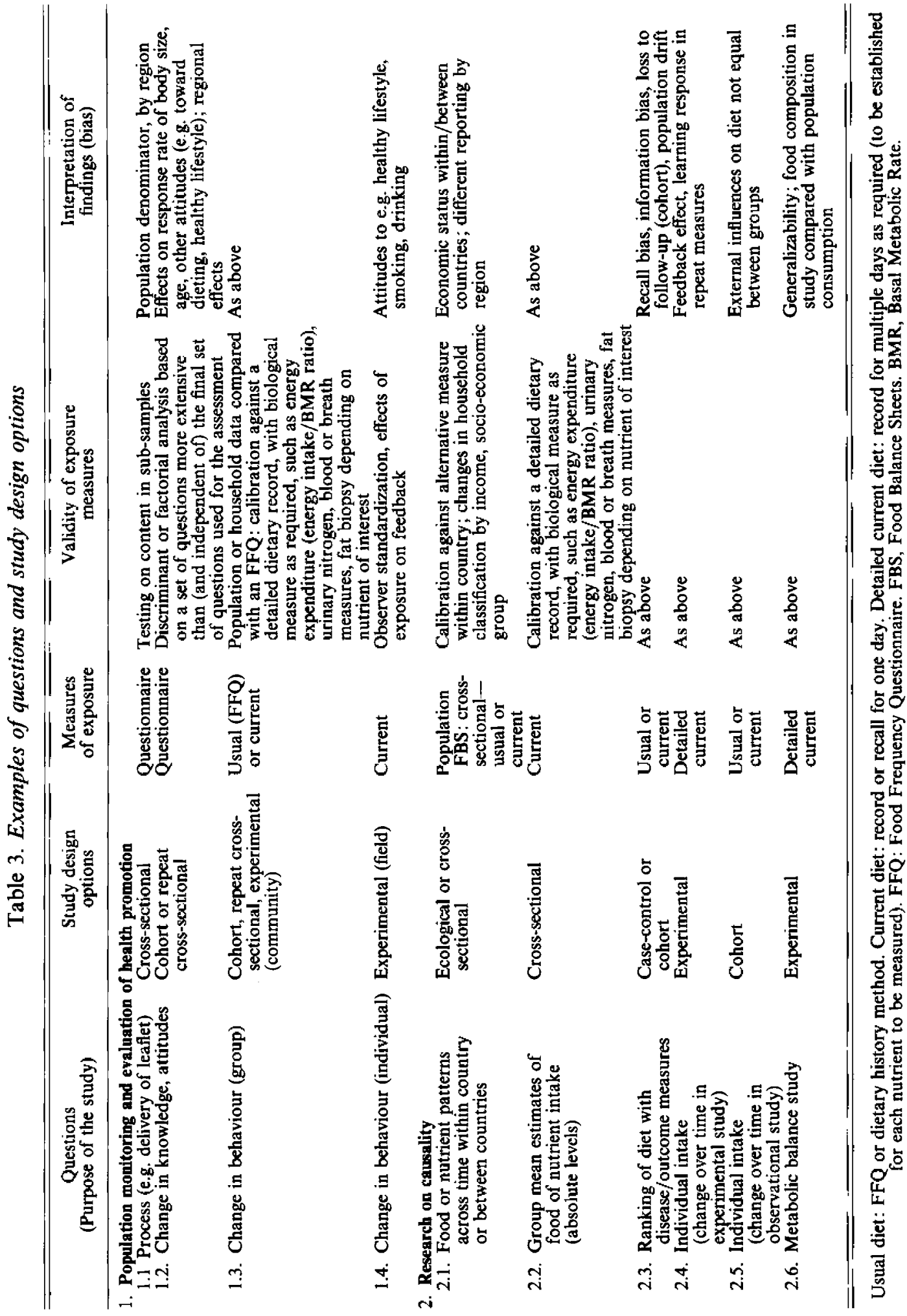




\section{SUMMARY}

It should be clear from the above that diet is a very complex exposure to measure. A study which develops from a clear research question in which exposure and outcome are clearly defined will help clarify the appropriate approach to be taken. The aim should be to measure the relevant exposure with required accuracy. The requirements for measuring dietary exposures differ with different types of study and the choice of assessment method and study design should be considered in the light of theoretical and practical considerations.

Because of the effect that misclassification of exposure may have on the interpretation of diet-disease relationships, it is desirable to have a measure of the likely misclassification which results from using the method selected. Depending on the type of misclassification either a repeat measure of the exposure should be included (random error) or inclusion of a different measure or an external marker of exposure (differential misclassification) may be appropriate. The measure may need to be measured only on a statistically viable subsample.

Ideally, before commencing the study, the most appropriate methods should be pretested and piloted in a relevant group.

The work presented here has developed out of discussions with colleagues who have participated in the UK Nutritional Epidemiology Group meetings held over the last seven years. While we accept full responsibility for the views expressed here we gratefully acknowledge our colleagues' support. BMM was in part financially supported by a grant from The Rank Prize Funds to The Institute of Human Nutrition.

\section{REFERENCES}

Ahmed, F., Barua, S., Mohiduzzaman, M., Shaheen, N., Bhuyan, M. A. H., Margetts, B. M. \& Jackson, A. A. (1993). Interactions between growth and nutrient status in school-age children of urban Bangladesh. American Journal of Clinical Nutrition 58, 334-338.

Barker, D. J. P., Winter, P. D., Osmond, C., Margetts, B. M. \& Simmonds, S. J. (1989). Weight in infancy and death from ischaemic heart disease. Lancet ii, 577-580.

Basiotis, P. P., Thomas, R. G., Kelsey, J. L. \& Mertz, W. (1989). Sources of variation in energy intake by men and women as determined from one year's daily dietary records. American Journal of Clinical Nutrition 50, $448-453$.

Bates, C. J., Thurnham, D. I., Bingham, S. A., Margetts, B. M. \& Nelson, M. (1991). Biochemical markers of nutrient intake. In Design Concepts in Nutritional Epidemiology, pp 192-265 [B. M. Margetts \& M. Nelson, editors]. Oxford: Oxford University Press.

Beaglehole, R., Bonita, R. \& Kjellström, T. (1993). Basic Epidemiology. Geneva: World Health Organization.

Bingham, S. A. (1987). The dietary assessment of individuals; methods, accuracy, new techniques and recommendations. Nutrition Abstracts and Reviews A 57, 705-742.

Bingham, S. A. \& Nelson, M. (1991). Assessment of food consumption and nutrient intakes. In Design Concepts in Nutritional Epidemiology, pp. 153-191 [B. M. Margetts \& M. Nelson, editors]. Oxford: Oxford University Press.

Block, G. (1982) A review of validations of dietary assessment methods. American Journal of Epidemiology 115, 492-505.

Block, G. (1992). Vitamin C status and cancer. Epidemiologic evidence of reduced risk. Annals of the New York Academy of Sciences 669, 280-292.

Block, G., Patterson B. \& Subar, A. (1992). Fruit, vegetables, and cancer prevention: a review of the epidemiological evidence. Nutrition and Cancer 18, 1-29.

Borrelli, R. (1990). Collection of food intake data: a reappraisal of criteria for judging the methods. British Journal of Nutrition 63, 411-417.

Bostick, R. M., Potter, J. D., Sellers, T. A., McKenzie, D. R., Kushi, L. H. \& Folsom, A. R. (1993). Relation of calcium, vitamin $\mathrm{D}$, and dairy food intake to incidence of colon cancer among older women: the lowa Women's Health Study. American Journal of Epidemiology 137, 1302-1317.

Breslow, N. E. \& Day, N. E. (1987). Statistical Methods in Cancer Research, IARC Scientific Publications No. 82, The Design and Analysis of Cohort Studies. Oxford: Oxford University Press. 
Cade, J. E., Barker, D. J. P., Margetts, B. M. \& Morris J. A. (1988). Diet and inequalities in health in three English towns. British Medical Journal 296, 1359-1362.

Cameron, M. E. \& Van Staveren, W. A., editors. (1988). Manual on Methodology for Food Consumption studies. New York: Oxford University Press.

Clayton, D. (1994). Measurement error: effects and remedies in nutritional epidemiology. Proceedings of the Nutrition Society 53, 37-42.

Clayton, D. \& Gill, C. (1991). Covariate measurement errors in nutritional epidemiology: effects and remedies. In Design Concepts in Nutritional Epidemiology, pp. 79-96 [B. M. Margetts and M. Nelson, editors]. Oxford: Oxford University Press.

Coggon, D. (1991). Case-control and cross-sectional studies. In Design Concepts in Nutritional Epidemiology, pp. 354-368 [B. M. Margetts and M. Nelson, editors]. Oxford: Oxford University Press.

Cole, T. J. (1991). Sampling, study size, and power. In Design Concepts in Nutritional Epidemiology, pp 53-78. [B. M. Margetts and M. Nelson, editors]. Oxford: Oxford University Press.

Freudenheim, J. L. \& Marshall, J. R. (1988). The problem of profound mismeasurement and the power of epidemiological studies of diet and cancer. Nutrition and Cancer 11, 243-250.

Giovannucci, E., Rimm, E. B., Stampfer, M. J., Colditz, G. A., Ascherio, A. \& Willett, W. C. (1994). Intake of fat, meat, and fiber in relation to risk of colon cancer in men. Cancer Research 54, 2390-2397.

Giovannucci, E., Stampfer, M. J., Colditz, G. A., Manson, J. E., Rosner, B. A., Longnecker, M., Speizer, F. E. \& Willett, W. C. (1993). A comparison of prospective and retrospective assessments of diet in the study of breast cancer. American Journal of Epidemiology 137, 502-511.

Gong, E. J., Garrel, D. \& Calloway, D. H. (1989). Menstrual cycle and voluntary food intake. American Journal of Clinical Nutrition 49, 252-8.

Gregory, J. Foster, K., Tyler, H. \& Wiseman, M. (1990). The Dietary and Nutritional Survey of British Adults. London: HMSO.

Hennekens, C. H. \& Buring, J. E. (1987). Epidemiology in Medicine. Boston, MA: Little, Brown and Co.

Kelsey, J. L., Thompson, W. D. \& Evans, A. S. (1986). Methods in Observational Epidemiology (Monographs in Epidemiology and Biostatistics vol. 10). New York: Oxford University Press.

Kohlmeier, L., editor. (1994). Dietary Assessment Resource Manual. Journal of Nutrition 124, Supplement 11.

Lindsted, K. D. \& Kuzma, J. W. (1989). Long-term (24 year) recall reliability in cancer cases and controls using a 21 -item food frequency questionnaire. Nutrition and Cancer 12, $135-149$.

Liu, K., Stamler, J., Dyer, A., McKeever, J. \& McKeever, P. (1978) Statistical methods to assess and minimize the role of intra-individual variability in obscuring the relationship between dietary lipids and serum cholesterol. Journal of Chronic Diseases 31, 399-418.

MacMahon, B., \& Pugh, T. F. (1970). Epidemiology: Principles and Methods. Boston, MA: Little, Brown and Co.

Margetts, B. M. (1994) Linking the field to the laboratory in nutrition research. Proceedings of the Nutrition Society 53, 43-52.

Medical Research Council Vitamin Study Research Group. (1991). Prevention of neural tube defects: results of the Medical Research Council Vitamin Study. Lancet 338, 131-137.

Meinert, C. L. (1986). Clinical Trials: Design, Conduct, and Analysis, Monographs in Epidemiology and Biostatistics, vol. 8. New York: Oxford University Press.

Nelson, M. (1991). The validation of dietary questionnaires. In Design Concepts in Nutritional Epidemiology, pp. 266-296 [B. M. Margetts and M. Nelson, editors]. Oxford: Oxford University Press.

Nelson, M., Black, A. E., Morris, J. A. \& Cole, T. J. (1989). Between- and within-subject variation in nutrient intake from infancy to old age: estimating the number of days required to rank dietary intakes with desired precision. American Journal of Clinical Nutrition 50, 155-67.

Renton, A. (1994). Epidemiology and causation: a realist view. Journal of Epidemiology and Community Health 48, 79-85.

Riboli, E. (1992). Nutrition and cancer: background and rationale of the European Prospective Investigation into Cancer and Nutrition (EPIC). Annals of Oncology 3, 783-791.

Rothman. K. J. (1986). Modern Epidemiology. Boston, MA: Little, Brown and Co.

Rouse, I. L., Armstrong, B. K., Margetts, B. M. \& Beilin, L. J. (1981). The dietary habits and nutrient intakes of Seventh-day Adventist vegetarians and Mormon omnivores. Proceedings of the Nutrition Society of Australia $6,117$.

Schlesselman, J. J. (1982) Case-control Studies: Design, Conduct, Analysis. New York: Oxford University Press.

Stemmermann, G. N., Nomura, A. M. Y. \& Heilbrun, L. K. (1984). Dietary fat and the risk of colorectal cancer. Cancer Research 44, 4633-4637.

van't Veer, P. (1994). Measuring nutritional exposures including biomarkers. Proceedings of the Nutrition Society 53, 27-35.

Willett. W. (1990). Nutritional Epidemiology. New York: Oxford University Press.

Willett, W. C., Reynolds, R. D., Cottrell-Hoehner, S., Sampson, L. \& Browne, M. L. (1987). Validation of a semi-quantitative food frequency questionnaire: comparison with a 1-year diet record. Journal of the American Dietetic Association 87, 43-47. 